\title{
PATROKLOU TAPHOS: LUTO, MUERTE Y VIOLENCIA EN MONUMENTOS FUNERARIOS DE LA ITALIA PRERROMANA
}

\author{
VALERIA RIEDEMANN LORCA \\ University of Oxford. ReinoUnido
}

Resumen: Este ensayo explora el uso del mito griego, particularmente el episodio del sacrificio de prisioneros troyanos ejecutado por Aquiles ante la tumba de Patroklos (Il. XXIII, 175-176) en monumentos funerarios de Apulia y Etruria en el siglo IV a.C. Mediante una comparación iconográfica, se analizará el significado del mito en la ideología funeraria de estas culturas.

Palabras Clave: Patroklos - Aquiles - mito - monumentos funerarios - Apulia - Etruria - recepción

\section{PATROKLOU TAPHOS: MOURNING, DEATH AND VIOLENCE ON PRE-ROMAN FUNERARY MONUMENTS}

\begin{abstract}
This paper explores the use of a Greek myth, in particular the episode of Achilles' sacrifice of the Trojan prisoners at Patroklos' tomb (Il. 23. 175-176) as depicted on funerary monuments of Apulia and Etruria in the fourth century BC. An iconographic analysis will allow us to conceptualise the meaning of the myth in the funerary ideologies of these cultures.
\end{abstract}

Keywords: Patroklos - Achilles - myth - funerary monuments - Apulia Etruria-reception theory

Recibido: 30.12 .15 - Aceptado: 30.03.2016

Correspondencia: Valeria Riedemann

Email: valeria.riedemann@gmail.com / valeria.riedemann@arch.ox.ac.uk Licenciada en Filosofía, Universidad de Chile. Magíster en Teoría e Historia del Arte, Universidad de Chile. Magíster en Arte y Arqueología Comparados, University College London. Doctor en Arqueología Clásica, University of Oxford.

Dirección: 38, Val Fleuri, L-1526 Luxemburgo 


\section{INTRODUCCIÓN}

Z1 episodio del sacrificio de los prisioneros troyanos a manos de Aquiles aparece en el contexto de los funerales de Patroklos en el libro XXIII de la Ilíada. Dentro de los ritos fúnebres celebrados en honor al difunto héroe, el sacrifico humano descrito en apenas dos versos (175-176) gozó de cierta popularidad en la Italia prerromana, donde encontramos las únicas manifestaciones visuales del mito. Ni los griegos, ni culturas al otro lado del Mediterráneo han dejado evidencia artística de un interés por este momento particular de la épica homérica. Por consiguiente, podríamos sostener que se trata de un tema que apeló especialmente a las sensibilidades de distintas culturas en la Península Itálica, entre ellas las de las regiones de Apulia y Etruria.

Al menos diez ejemplos de Aquiles sacrificando a los troyanos hechos en el siglo IV a.C. han llegado a nosotros en diversos tipos de monumentos y de diferentes regiones. Entre ellos, contamos siete ejemplos etruscos (dos vasos, cuatro sarcófagos y una pintura mural), dos o tres cistas de bronce hechas en Praeneste y un vaso encontrado en el norte de Apulia (Canosa $)^{1}$. Algunos estudios han encontrado relaciones entre el mito y hechos históricos contemporáneos a su propagación: por ejemplo, en el contexto de confrontaciones entre etruscos y romanos, Livio nos cuenta que 307 nobles romanos fueron sacrificados en el foro de Tarquinia en 358 a.C., y que cuatro años después los romanos harían lo mismo con 354 aristócratas tarquinienses en su propio foro ${ }^{2}$. No obstante, el tema del sacrificio también es adecuado en un contexto funerario y en este sentido no podemos descartar la convincente teoría, propuesta por Jaques Heurgon, de que el macabro episodio haya sido escogido en reemplazo de reales sacrificios humanos celebrados en Etruria a partir de 350 a.C. ${ }^{3}$. La evidencia arqueológica encontrada hasta la fecha indica que, probablemente, se realizaron sacrificios humanos en distintos contextos, incluido uno postmortem $^{4}$. Sin embargo, algunos estudios se oponen a reconocer la posibilidad

1 Véase Maggiani (1985), pp. 208-210; LIMC, Achle, núm. 85-95.

2 Livio VII. 15.10; VII. 19. 2 -4.

3 Heurgon (1961), p. 244.

$4 C f$. Donati (2004), pp. 136-139. Posibles sacrificios humanos en Pian de Civita (Tarquinia) han sido mencionados por Haynes (2000), pp. 27-28. No obstante, no todas las matanzas rituales en esta área tienen relación con la fundación de algún edificio, puesto que hay sólo dos casos en los que se realizaron sacrificios humanos 
de esta práctica en un contexto funerario ${ }^{5}$.

A continuación, se analizará los tipos de monumento donde se presenta el tema del sacrificio a manos de Aquiles seguido de una comparación iconográfica entre éstos. El énfasis en distintos atributos que veremos en la cerámica ápula y en monumentos etruscos nos conducirá a un análisis más profundo del mito y la pertinencia de su uso funerario.

\section{1.-Patroklou taphos (la tumba de Patroklos).}

El único ejemplo del sur de Italia lo provee una crátera ápula de volutas pintado con la técnica de figuras rojas y atribuido al Pintor de Darío y fue encontrada en 1851 en un hipogeo funerario en la localidad de Canosa en Apulia (moderna Puglia) ${ }^{6}$. La crátera, de grandes dimensiones $(130 \mathrm{~cm})$, era parte de un grupo de cinco vasos monumentales de la mano del mismo pintor: una crátera de volutas con Darío y los persas (que dio el nombre al pintor), un lutróforo decorado con la historia de Andrómeda y un par de ánforas panatenaicas con el mito de Europa y el toro en una, y el de Medea en la otra. ${ }^{7}$

La escena de la crátera con los funerales de Patroklos, se encuentra repartida en diferentes registros donde se reparten diversos grupos animados, cada uno cargando un particular pathos (Fig. 1). La pira funeraria, ornamentada con las armas del héroe, porta la inscripción ПАТРОК $\Lambda$ ОY ТАФО $\Sigma$ (la tumba de Patroklos), donde su centralidad y aspecto monumental le confieren un valor paralelo al naiskos funerario que se observa en un centenar de imágenes en la cerámica ápula y cuyos restos también se han encontrado en necropoleis en Taranto y en Atenas ${ }^{8}$. Luego, a la izquierda, el prisionero que Achiles se apronta a masacrar y un grupo de troyanos encadenados y humillados que esperan su

Véase, Bonghi Jovino(2010), pp. 161-180, esp. pp. 165-166.

5 Por ejemplo, Steuernagel (1998), pp. 149-166.

6 Nápoles, Museo Archeologico Nazionale 3254; RVAp II 495, núm. 18/30.

7 Fue M. Schmidt (1960) quien establece el nombre de "Pintor de Darío" y estudió su obra en la cerámica ápula conformada por cerca de 150 vasos. Para estudios sobre el hipogeo y los vasos, véase Cassano (1992), pp. 176-186; Pouzaduox (2013), pp. 115-129.

8 Cf. Carter (1975). 
turno; a la derecha, Agamenón vertiendo una libación. En el registro inferior, se observa el cuerpo de Héctor tirado por el carro de Automedon, mientras que en registro superior Néstor y Fénix dialogan en una tienda del campamento griego.

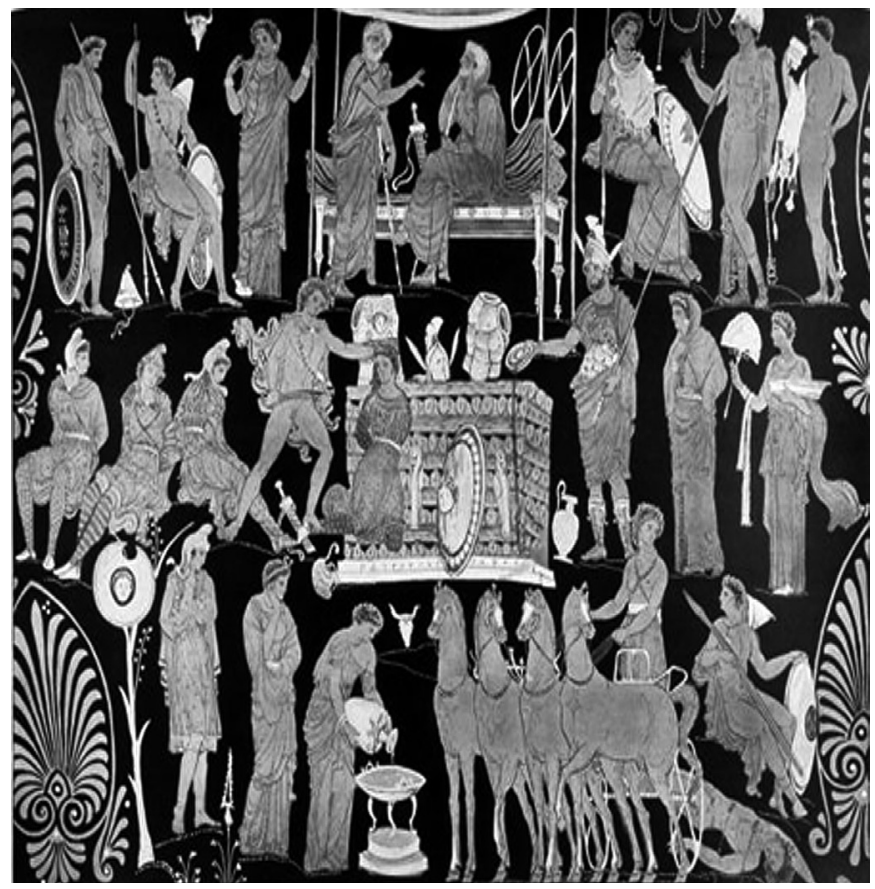

Fig. 1. Crátera de volutas atribuida al Pintor de Darío, Funerales de Patroklos (340330 a.C.). Furtwängler-Reichhold (1906), Griechische Vasenmalerei: Auswahl hervorragender Vasenbilder, München: Bruckmann, ill. 89.

Como se ha señalado, el episodio representado en esta crátera era parte de un grupo funerario más amplio con otros mitos y una escena histórica aludiendo a un episodio en la corte de Darío. El conjunto intenta destacar el carácter heroico de los personajes representados y, en el caso de los funerales de Patroklos en particular, la centralidad de la tumba del héroe y los ritos celebrados en su honor conforman una temática adecuada para el contexto de este monumento, donde el duelo de Aquiles y su sed de venganza aparecen representados de forma idealizada, aludiendo a la "bella muerte" característica de la cerámica ápula inspirada en episodios trágicos ${ }^{9}$.

9 Cf. Taplin (2007). 


\section{Hinthial Patrukles (la sombra de Patroklos).}

A diferencia de Apulia, el episodio troyano se encuentra con más frecuencia en monumentos etruscos, siendo el tema de un sarcófago de Tarquinia, otro de Orvieto (Torre San Severo) y una pintura funeraria de Vulci. ${ }^{10}$ En estos monumentos, el episodio aparece yuxtapuesto a otros mitos de temática similar, conformando así los llamados "paralelismos visuales" frecuentes en el arte etrusco $^{11}$.

Comenzaremos analizando el ejemplo de la Tumba François proveniente de Vulci ya que esta pintura mural no sólo ofrece un esquema definido, sino que también provee al espectador con los nombres de los personajes representados en su transliteración etrusca (Fig. 2). La tumba, dedicada a la familia de VelSaties (inscripción) fue descubierta por Alessandro Francois en 1857 en la necrópolis de Ponte Rotto. Se accedía a ella por un largo corredor (dromos) de $27 \mathrm{~m}$ y constaba de una antesala (atrium), tablinum y siete cámaras funerarias. Las paredes del atrium y tablinum estaban decoradas con frescos datados en la segunda mitad del siglo IV a.C. Sin embargo, hallazgos más antiguos sugieren que la tumba se encontraba en uso desde mediados del siglo V a.C. ${ }^{12}$. Los frescos fueron removidos poco después de su descubrimiento y han sido custodiados en la Villa Albani, Roma, desde $1946^{13}$.

10 Aunque no tan claramente definido como en estos monumentos, puede que el tema también esté representado en otro sarcófago de Tarquinia, hoy en Londres (British Museum D21).

$11 C f$. Van der Meer (1985), pp. 72-83.

12 Por ejemplo, una ánfora ática de figuras rojas (ca. 475 a. C.) hoy en Bruselas (Musée du Cinquantenaire R 303); $A R V^{2} 165.5$; CVABrussels, lám. 35-36.

13 Tras su última restauración, los frescos fueron exhibidos en Hamburgo y en Vulci en 2007. Sin embargo, luego de que la familia Torlonia rechazara vender los frescos al gobierno italiano, éstos “desaparecieron” en alguna sala de la Villa Albani. Hoy no es posible visitarlos. 


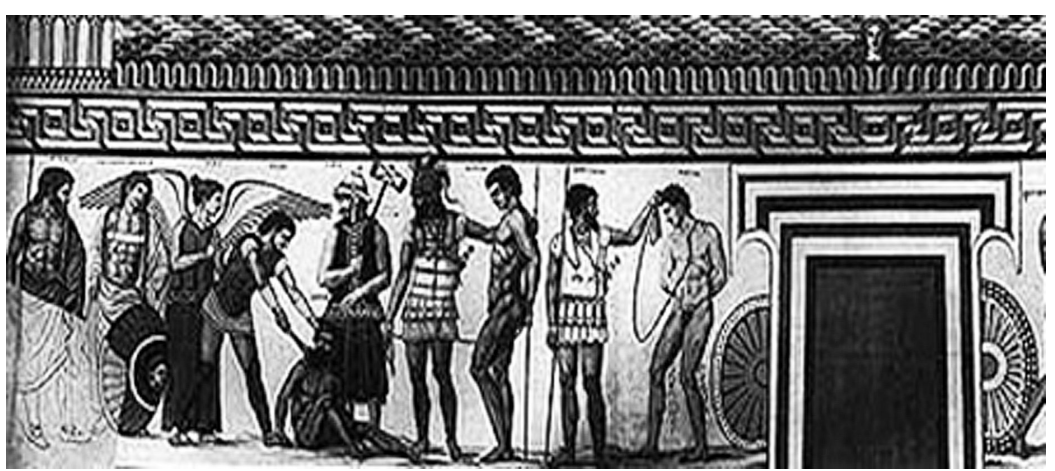

Fig. 2. Tumba François (Vulci), Sacrificio de los prisioneros troyanos (ca. 325 a.C.). Copia de Carlo Ruspi (acuarela) en el Museo Gregoriano Etrusco, Roma.

Tal como en la representación del tema por parte del Pintor de Darío, el fresco de Vulci presenta una escena central organizada en torno a Aquiles y su víctima, ubicada en la pared izquierda del tablinum. De izquierda a derecha, se observan los siguientes personajes: Agamenón (Axmenrum), la sombra de Patroklos (hinthial Patrukles), Vanth (Vanth), Aquiles (Axle), un troyano (Truials), Áyax Telamonio (Aivas Tlamunus), otro troyano (Truials), Áyax Oileo (Aivas Vilatas), y otro troyano (Truials). En el centro, vemos a Aquiles cortando la garganta de un troyano sentado en el suelo, acción observada por un noblemente ataviado Agamenón; a la extrema izquierda, un griego y la sombra de Patroklos observan el sacrificio. El difunto héroe lleva una venda blanca atada alrededor del pecho señalándonos, de esta manera, sus heridas fatales. Entre Patroklos y Aquiles se encuentra Vanth, la divinidad femenina etrusca de la muerte, con sus alas desplegadas simbólicamente abrazando a ambos héroes, ya que pronto ella también ha de llevarse a Aquiles ${ }^{14}$. A la derecha del grupo se encuentra su contraparte masculina, el Caronte etrusco (Charun), portando su usual martillo. Le sigue Áyax Telamonio sosteniendo a un prisionero troyano con su brazo extendido. La escena se extiende por la pared del fondo hasta el lado izquierdo de la entrada a una cámara funeraria donde se observa a Áyax Oileo conteniendo a un tercer prisionero troyano con una cuerda. Los tres troyanos están desnudos, y los dos de pie tienen sus manos atadas por la

14 Pallotino (1952), p. 118; Massa-Pairault (1992), 118. Las alas de Vanth se observan más claramente en la copia hecha por Carlo Ruspi en el siglo XIX (hoy en el Museo Gregoriano Etrusco, Vaticano) que en lo que queda del fresco. 
espalda, como se cuenta en la Ilíada ${ }^{15}$.

Una composición similar se encuentra en un sarcófago proveniente de la tumba de la familia Partunu, en Tarquinia. Este se encontraba junto a otros 25 sarcófagos demostrando que la tumba fue usada por varias generaciones. Descubierto en 1876, el sarcófago conocido como "sarcófago del sacerdote", es el único del grupo cuya decoración es pintada y no esculpida (Fig. 3). La lápida, muestra una figura masculina plana sosteniendo un pyxis en su mano izquierda de forma similar a las figuras en algunos sarcófagos de Cartago, lo que sugiere que este monumento fue importado a Etruria donde fue pintado ${ }^{16}$. El lado largo A, muestra la escena de Aquiles sacrificando a los troyanos enmarcado por amazonomaquias, una iconografía sin precedentes en otros monumentos. Éstas se componen de una amazona y un guerrero caído, mientras que visten una larga túnica y están armadas con espadas y escudos, pero no con el tradicional pelta en forma de media luna.

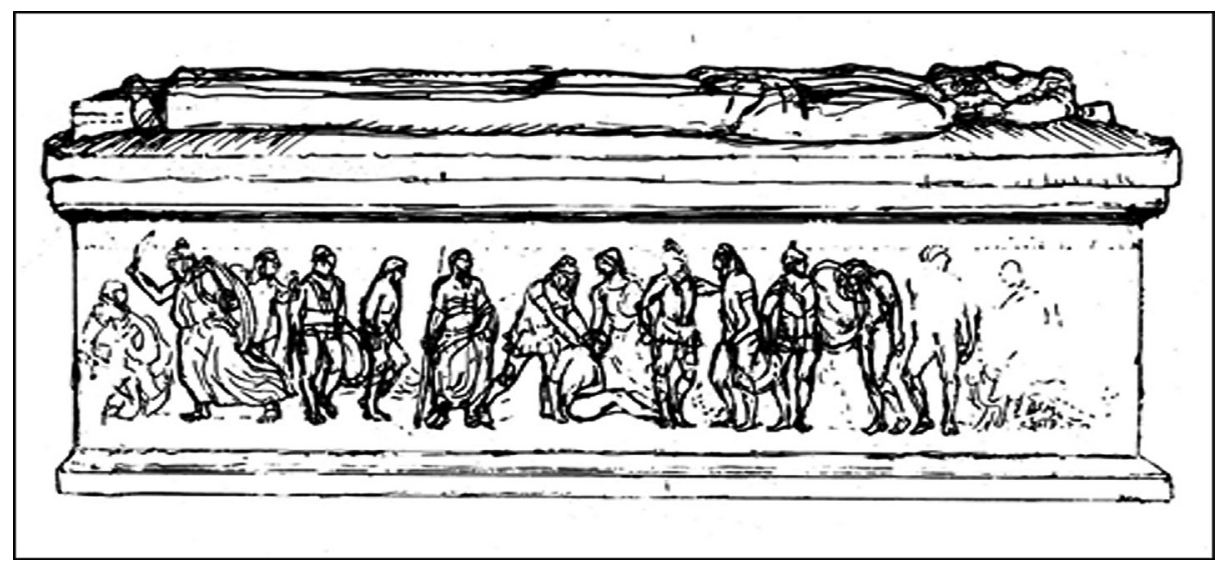

Fig. 3. "Sarcófago del sacerdote" (Tarquinia), Sacrificio de los prisioneros troyanos (ca. 350 a.C.). Dibujo de Danilo Sepúlveda (2013).

15 Il. XXIII, 30.

16 Macintosh-Turfa (1986); Martelli (1975), pp. 9-17. 
La escena central se compone, de izquierda a derecha, del Caronte etrusco (Charun), un guerrero griego, un prisionero troyano de pie, Patroklos vendado, Aquiles sacrificando a un troyano sentado y una figura no identifica, posiblemente Vanth sin alas ${ }^{17}$. A este grupo le siguen los dos Ayantes, diferenciados por sus distintas estaturas, cada uno sosteniendo un prisionero junto a otro guerrero griego ${ }^{18}$. Los griegos están vestidos y armados en contraste a los prisioneros troyanos que están desnudos. A diferencia de la Tumba François, las figuras no llevan inscripciones, pero como hemos señalado, el tema tiene paralelos iconográficos en monumentos contemporáneos que permiten su clara identificación ${ }^{19}$.

Por otra parte, el lado largo B y los lados cortos del sarcófago muestran amazonomaquias. Mientras que éstas últimas se componen de una amazona montada a caballo y un guerrero caído (uno de ellos siendo llevado por un demonio alado), en el lado largo B combaten a pie donde trece figuras están organizadas en cuatro grupos. Demonios de la muerte se llevan a los guerreros caídos, mientras que en el último grupo no está claro si la figura femenina caída está siendo llevada por un demonio o asistida por una compañera. Este motivo iconográfico nos es conocido por copias del escudo de la Atenea Parthenos en Atenas, pero este es el único ejemplo de un posible "helpergroup" en sarcófagos etruscos. ${ }^{20}$ No obstante, el motivo aparece con frecuencia en la pintura de vasos griegos que eran parte de la cultura visual de los etruscos y, por lo tanto, el pintor pudo haberse inspirado en ellos.

Por último, la escena de Aquiles se encuentra también en un sarcófago proveniente de Torre San Severo, cerca de Orvieto, encontrado en una tumba en 1916 (Fig. 3). La autenticidad del sarcófago fue cuestionada por algunas décadas, pero la opinión actual es que se trata de un trabajo original hecho por

$17 C f$. Van der Meer (2004), p. 33.

18 Aunque los Ayantes representados en este sarcófago y en la Tumba François no aparecen mencionados en Il. XXIII, sí aparecen en otros libros de la Ilíada donde frecuentemente combaten juntos. Véase D'Agostino (2003), pp. 105-107; Van der Meer (2004), p. 32.

19 Para una discusión sobre el tema de la escena central de este sarcófago, véase Blanck (1982) y (1983), pp. 79-84.

20 Para los distintos motivos en el escudo de la Atenea Parthenos, véase Harrison (1981), ill. 11. 
artistas locales. ${ }^{21}$ El sarcófago está esculpido en sus cuatro lados: el lado largo A muestra el sacrificio de los prisioneros troyanos a manos de Aquiles flanqueado por la diosa Lasa y Charun. En el centro, se observa a Aquiles sosteniendo a la víctima por el cabello, mientras que con la otra mano sostiene el cuchillo con el que traspasa su garganta de lado a lado. Detrás de ellos, se encuentra la sombra de Patroklos llevando vendajes alrededor de su pecho y cabeza, mientras apoya una mano en su propio monumento funerario. A la izquierda de la escena central y detrás de un troyano muerto están Perséfone y Hades ${ }^{22}$. A la derecha, se encuentran probablemente los dos Ayantes y más troyanos.

El lado largo B muestra una temática similar: un monumento funerario, la sombra de un hombre herido, y otro hombre sacrificando a una figura femenina con su espada frente a varios testigos. Esta vez, se trata de Neoptólemo sacrificando a Polixena frente a la tumba de Aquiles, su padre. La sombra del héroe aparece vendada en el pecho y cabeza, de igual forma que Patroklos en el lado largo A. A la izquierda, un hombre porta un bastón curvado, probablemente una especie de sacerdote, junto a un hombre que podría ser Néstor o Calcas, y Agamenón portando el cetro. A la derecha, Ulises y dos guerreros más.

Los lados cortos del sarcófago muestran episodios de la Odisea: Ulises amenazando a Circe en un lado, y Ulises sacrificando un cordero antes de su entrada al Hades en el otro ${ }^{23}$.

21 Cf. Cagiano de Azevedo (1970), pp. 10-18; Van der Meer (2004), p. 30.

22 La identificación de la pareja es sugerida por una representación similar con inscripciones en la Tumba del Orco II (aunque en el sarcófago, Hades no lleva el sombrero de lobo que porta en la tumba). Véase Galli (1916), pp. 44-47.

23 Od. X, 319-326 y XI, 23 respectivamente. 


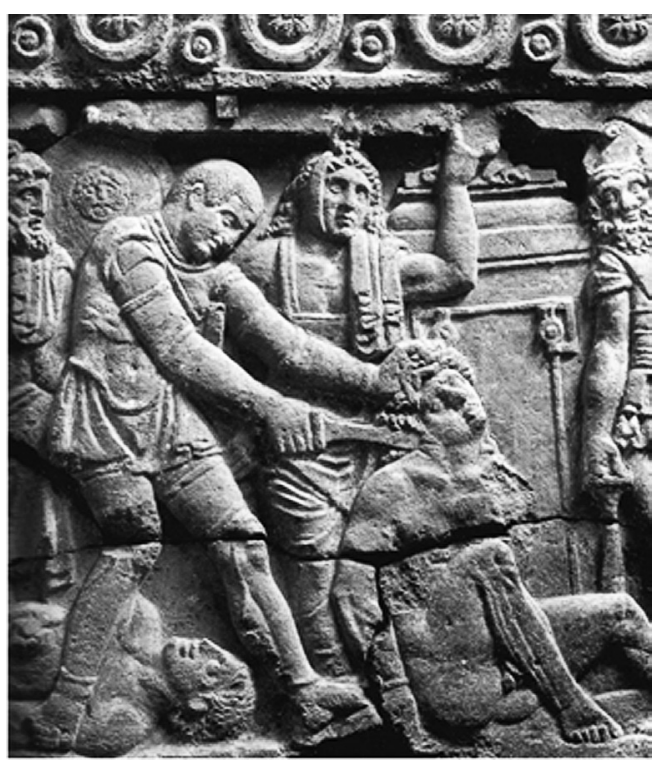

Fig. 4. Sarcófago de Torre San Severo (detalle). Sacrificio de los prisioneros troyanos (ca. 350 a.C.). Museo Claudio Faina, Orvieto. Foto de la autora.

La descripción iconográfica de los monumentos etruscos recién analizados permite hacer ciertas observaciones y establecer comparaciones entre ellos. Por ejemplo, la sombra de Patroklos reemplaza, en algunos casos, a su tumba. Sin embargo, en las tres versiones hay un énfasis en el acto del sacrificio mismo, esto es, en mostrar a Aquiles sacrificando a sus víctimas de manera explícita y no sólo de manera amenazante como en el ejemplo ápulo. 


\section{Sacrificio para la tumba: algunas consideraciones contextuales del mito.}

Los cuatro monumentos descritos, uno ápulo y tres etruscos, muestran el tema del sacrificio claramente representado y utilizan una iconografía similar. No obstante, las versiones etruscas suelen incorporar elementos ajenos a la narrativa homérica como lo son, por ejemplo, demonios de la muerte etruscos (Charun y Vanth), y las sombras de los muertos a quienes se rinde el sacrificio (Patroklos y Aquiles).Examinemos, a continuación, los versos homéricos que inspiraron la escena:

“... [Aquiles] inmoló doce jóvenes troyanos, hijos de familias nobles con el bronce, pues su corazón estaba lleno de instintos crueles"24.

De las versiones examinadas hasta ahora, la del Pintor de Darío parece estar más cerca del texto homérico: vemos la pira funeraria (mencionada en los versos precedentes) y, junto a ella, objetos depositados en honor al difunto como por ejemplo, un ánfora ${ }^{25}$. También vemos a Agamenón vertiendo un líquido oscuro desde un phiale, probablemente sangre de los animales previamente sacrificados ${ }^{26}$. La demás escenas pintadas en la crátera, basadas en el mismo canto, nos dan cuenta de que el pintor (o el comitente del vaso) tenía un especial interés por los episodios narrados en el libro XXIII de la Ilíada y que las imágenes del vaso traducen de manera más o menos aproximada. Por ejemplo, los troyanos aparecen vestidos a la manera oriental, con pantalones, mangas largas y sombreros frigiospara indicar al espectador su diversa etnicidad en contraste a los griegos, cuya desnudez heroica es característica del arte griego en vasos y esculturas.Por el contrario, en la versiones etruscas, los troyanos aparecen desnudos en contraste a los griegos, siempre vestidos.

La mayoría de los etruscólogos concuerdan con la interpretación de que las escenas del sacrifico de los prisioneros troyanos ilustradas por artistas etruscos desde mediados del siglo IV a. C., llevan consigo alusiones contrarias a los romanos, y que los conflictos bélicos entre ambas partes durante este tiempo motivaron la aparición del tema ${ }^{27}$. De hecho, algunos han visto un elemento

24 Il. XXX, 175-176, traducción libre de la autora.

25 Il. XXX, 170-171.

26 Ibid. 172-174.

27 Coarelli (1985) y especialmente Massa-Pairault (1992), pp. 118-125. 
propagandista en estas pinturas y relieves, donde los romanos son asociados a los troyanos y los etruscos a los griegos. ${ }^{28}$ Esta hipótesis podría ser válida si asumimos que estos monumentos funerarios eran exhibidos públicamente durante el funeral. Sin embargo, no tenemos documentos etruscos que sustenten estos argumentos ideológicos, sino sólo teorías basadas en evidencia arqueológica la que, hasta ahora, no ha dado indicios de escenas como estas pintadas o esculpidas en monumentos públicos - un lugar, por cierto, más apropiado para desplegar tal mensaje. Las variaciones iconográficas del tema en Etruria indican que no había un modelo original copiado por los artistas, sino que cada uno tomó los elementos básicos y configuró su propia creación original.

Que el mayor número de representaciones provenga de Etruria no implica, necesariamente, que hayan sido los etruscos quienes introdujeron el tema en otras regiones de la Península Itálica como Apulia o Latium, ya que no podemos descartar que el episodio homérico haya existido en algún original griego o italiota perdido para siempre y del que no tenemos registro. A este problema, se suma el de la datación de los monumentos, puesto que no es posible saber con certeza cuál se creó primero. Por ejemplo, la versión ápula del Pintor de Darío está datada entre 340 y 330 a.C., una cista de bronce grabada con la escena hoy en Londres, más conocida como cista Révil, ha sido datada entre 360 y 300 a.C., mientras que una fecha de $c a .350$ a.C. ha sido propuesta para la pintura del "sarcófago del sacerdote", los relieves del sarcófago de Torre San Severo y los frescos de la Tumba François. En el caso de la última, se ha propuesto la actual - y aceptada opinión - de que los frescos fueron hechos antes de que los romanos obtuvieran la hegemonía en Vulci, esto es, antes de 280 a.C. ${ }^{29}$.

En la versión del Pintor de Darío, Patroklos aparece sólo indirectamente mencionado por la inscripción en su tumba (Patroklou taphos), mientras que los artistas de las tres versiones etruscas que hemos analizado nos muestran su "sombra" (hinthial Patrukles) llevando vendajes para recordarnos de sus heridas mortales. Sólamente en el caso de Orvieto vemos los dos elementos combinados: tumba y difunto. Otro detalle que aparece en los tres casos es

28 Ejemplos de propaganda anti romana se encuentran en Steingräber (1986), núm.

178 y 69; Van der Meer (2004), pp. 29-32, figs. 7-10; Minder (2008), pp. 77-99.

29 Steingräber (1986), p. 387. 
notable: Aquiles lleva el cabello corto, tal como lo señala el texto homérico ${ }^{30}$. Esta cercanía con el texto es particular si consideramos que en el arte griego, el héroe generalmente aparece con el cabello largo. Una estatuilla en bronce (400-350 a.C.) encontrada en el puerto etrusco de Spina muestra a Aquiles en el acto de cortar sus cabellos con una daga ${ }^{31}$. Por consiguiente, podemos inferir que para los etruscos el duelo de Aquiles y los deberes fúnebres para con su compañero Patroklos eran importantes aspectos a ser resaltados, en especial si consideramos que estas representaciones fueron concebidas con un propósito funerario.

Igualmente importante es la yuxtaposición del episodio del sacrificio de los troyanos con otros mitos en los monumentos analizados. Esta práctica no es exclusiva de los monumentos funerarios, puesto que el hábito de asociar mitos tiene una larga tradición desde que la pintura de vasos se difundió en Italia. Por ejemplo, en la Tumba François, el tema aparece junto a una batalla histórica, mitos troyanos y tebanos, y otras figuras heroicas. En el "sarcófago del sacerdote", el episodio aparece rodeado de amazonomaquias, mientras que en el sarcófago de Torre San Severo el escultor ha seleccionado cuatro escenas unidas por composición y temática similares. Por ejemplo, vemos que en cada escena un hombre sacrifica o amenaza a su víctima, ésta última siempre en el lado derecho. Temáticamente, en los cuatro lados prevalece la idea de muerte cercanamente conectada con la de sacrificio, que se enfatiza no sólo por la presencia de divinidades etruscas, sino que también por la presencia de Hades y Perséfone siendo testigos de la inmolación de los troyanos, las sombras de Patroklos y Aquiles observando la sangre vertida en su honor, y los griegos sacrificando a Polixena y a otros troyanos. De hecho, es posible encontrar paralelismos en los lados largos: mientras Aquiles venga y honra a Patroklos, el otro lado muestra a Patroklos sacrificando una víctima en honor a su padre. En ambos casos las sombras de los muertos presencian el sacrificio. Por consiguiente, la consagración de Aquiles a su compañero es comprada al deber de un hijo hacia su padre. En los lados cortos, se observa a Ulises en momentos clave para su regreso a Ítaca, incluyendo una escena de sacrificio. De este modo, el programa iconográfico del sarcófago de Torre San Severo, como el de los otros monumentos, está basado en episodios clave de los poemas homéricos, yuxtaponiendo valores de retribución y de honra a los difuntos. En

30 Il. XXIII, 150-151.

31 Ferrara, Museo Archeologico 2307; LIMC, Achle, núm. 95. 
VALERIA RIEDEMANN LORCA: Patroklou taphos: luto, muerte y violencia...

todos ellos, queda en evidencia un especial interés por episodios violentos y motivos sangrientos, como muestra la siguiente tabla (Tab. 1):

\begin{tabular}{|c|c|c|c|c|}
\hline Monumento & $\begin{array}{c}\text { Fecha } \\
\text { (a.C.) }\end{array}$ & Proveniencia & Otros Mitos & $\begin{array}{c}\text { Ocupante/ } \\
\text { destinatario }\end{array}$ \\
\hline $\begin{array}{c}\text { Crátera de } \\
\text { volutas }\end{array}$ & $340-330$ & Canosa & hombre \\
\hline $\begin{array}{c}\text { Tumba } \\
\text { François }\end{array}$ & $330-300$ & Vulci & $\begin{array}{c}\text { Ajax y Casandra, Néstor, } \\
\text { Eteocles y } \\
\text { Polinices, Sísifo y } \\
\text { Anfiaraos }\end{array}$ & varios \\
\hline $\begin{array}{c}\text { Sarcófago } \\
\text { del }\end{array}$ & $350-340$ & Tarquinia & $\begin{array}{c}\text { Amazonomaquia } \\
\text { Sacerdote }\end{array}$ & hombre \\
\hline $\begin{array}{c}\text { Sarcófago } \\
\text { de Torre San } \\
\text { Severo }\end{array}$ & $350-325$ & Orvieto & $\begin{array}{c}\text { Polixena, Ulises } \\
\text { Circe, Ulises } \\
\text { sacrificando un } \\
\text { cordero }\end{array}$ & hombre \\
\hline
\end{tabular}

Tab. 1. Mitos yuxtapuestos al episodio de Achiles sacrificando a los troyanos en monumentos funerarios de Apulia y Etruria. 
En relación al significado del episodio de Aquiles inmolando a los troyanos, se ha notado que independiente de la composición, la presencia de Agamenón en la escena legitima la violencia ejercida por el héroe contra sus víctimas ${ }^{32}$. En este sentido, el mensaje sugerido por el episodio, donde Aquiles ejerce sus deberes en honor al difunto Patroklos, parece haber sido apropiado para los miembros de las familias Saties (Tumba François) y Partunu ("sarcófago del sacerdote") durante generaciones ${ }^{33}$.

La muestra explícita de sacrificios humanos, muerte y violencia en el arte etrusco puede generarnos, por cierto, aversión; pero debemos considerar que castigo y venganza eran las únicas formas de ejercer justicia en la antigüedad $^{34}$. Como resultado, la violencia ejercida por Aquiles es justificada y venerada. Alternativamente, el episodio también implica el fin de la ira del héroe, lo que se muestra por la presencia de Agamenón en la escena durante el sacrificio y que, a la larga, contribuye a la unidad (homonoia) que los griegos necesitaban para vencer a los troyanos ${ }^{35}$. Por último, en el sarcófago de Torre San Severo, Aquiles es representado vivo y muerto, mostrándonos que incluso los más grandes héroes son también mortales.

\section{CONCLUSIONES}

Algunos temas derivados de la épica homérica no previamente abarcados por artistas griegos fueron, sin embargo, del interés de artistas y comitentes en la Península Itálica, donde estas temáticas sirvieron para articular ideas propias. El episodio de Aquiles sacrificando a los prisioneros troyanos en honor a Patroklos es un ejemplo de ello, donde en la mayoría de los casos analizados, el episodio aparece representado en una fórmula que nos es conocida por la Ilíada. Sin embargo, hemos visto que en cada una de ellas hay variaciones, siendo las más evidentes las de las versiones etruscas que añaden demonios locales, las "sombras" de aquellos que han partido o a los dioses del ultramundo. El hecho de que los nombres de los héroes aparezcan inscritos

$32 C f$. Maggiani (1985).

33 Para los nombres de los miembros de la familia Saties inscritos en la Tumba Francois, véase Buranelli (1987), pp. 147-162.

34 Cf. Älfoldi (1965), p. 224.

35 Sobre discordia y concordia en la Tumba François, véase D’Agostino (2003), p. 106; Musti (2005), pp.489-495; Cerchiaiet al. (2015), pp. 316-317. 
en etrusco y no en griego (como en el caso de Apulia), sugiere que los artistas etruscos se basaron en una fuente oral o una versión etrusca de los poemas homéricos para sus representaciones.

El episodio apeló a sensibilidades itálicas y etruscas, pues parece haber portado un valor ideológico en el siglo IV a.C., cuando fue representado en diversos monumentos. La traducción visual de narrativas mitológicas griegas permitió a estas culturas poder articular diferentes ideas acerca del mundo en el cual vivieron, incluyendo sus preocupaciones sobre la vida en el más allá. Por lo tanto, si efectivamente algunos mitos son el reflejo de las circunstancias históricas que afectaron a los ápulos y etruscos durante este periodo, como lo fue el creciente poder y conquista de Roma, esto no excluye la posibilidad de que, al mismo tiempo, estas representaciones intentaran conciliar necesidades específicas para el ritual funerario. En este contexto, las escenas de sacrificio nos revelan la importancia del derramamiento de sangre en el arte funerario, ya que este rito era esencial en el culto de los muertos (al menos en Etruria). Los comitentes ápulos y etruscos querían ver escenas violentas y el trágico destino de los héroes de la mitología griega representados en sus monumentos funerarios para honrarse a sí mismos y a sus muertos. Estas escenas también advierten a los sobrevivientes sobre la importancia del rito fúnebre y el culto a los antepasados, incluyendo su continuidad en el tiempo una vez que la tumba fuese sellada para siempre. 


\section{REFERENCIAS BIBLIOGRÁFICAS}

ARV² BEAZLEY, J.D. (1963).Attic Red-Figure Vase-Painters. 2nd ed. Oxford: Clarendon Press.

CVA CORPUS VASORUM ANTIQUORUM (varias ediciones).

LIMC LEXICON ICONOGRAPHICON MYTHOLOGIAE CLASSICAE (19811989). Zurich and Munich: Artemis.

RVAP TRENDALL, A.D. AND A. CAMBITOGLOU (1978-1982). The RedFigured Vases of Apulia, I-II. Oxford and New York: Clarendon Press and Oxford University Press.

ALFÖLDI, A. (1965). EARLY ROME AND THE LATINS. LONDRES: ANN ARBOR.

BLANCK, H. (1982). "Die Malereien des sogennanten Priester-Sarkophages in Tarquinia". En: Miscellanea Archaeologica Tobias Dohrn. Rome: Bretschneider.

BLANCK, H. (1983).“Le pitture del sarcofago del sacerdote nell museo nazionale di tarquinia”, Dialoghi di Archeologia I, 2, 79-84. Milán: Il Saggiatore II di Alberto Mondadori Editore.

BONGHI JOVINO, M. (2010). "The Tarquinia Project: A Summary of 25 Years of Excavation", American Journal of Archaeology, 114(1), 161180. Boston, MA: Archaeological Institute of America.

BURANELLI, F. (1987). La Tomba François di Vulci. Rome: Quasar.

CAGIANO DE AZEVEDO, M. (1970). "L'autenticità del sarcofago di Orvieto da Torre San Severo", Mitteilungen des Deutschen Archäologischen Instituts, Römische Abteilung, 10-18. Roma: Deutsches Archäologisches Institut.

CASSANO, A.(1992). Principi Imperatori Vescovi: Duemila anni di historia a Canosa. Bari: Marislio.

CARTER, J. C. (1975). The Sculpture of Taras. Philadelphia: American Philosophical Society.

COARELLI, F. (1985). "Le pitture della Tomba François a Vulci. Una proposta di lettura", Ricerche di pittura ellenistica. Quaderni dei Dial Arch. Rome.

CERCHIAI, L., LUBTCHANSKY, N., AND POUZADOUX, C. (2015). "Du bon usage de la violence dand l'iconographie italiote et étrusque". En : R. Roure (ed.), Contacts et acculturations en Méditerranée Occidentale. Hommage à Michel Bats. Arles. Paris: Errance.

D’AgOSTINO, B. (2003). "Appunti in margine alla Tomba François di Vulci”. En: A. Minetti (ed.), Pittura Etrusca: Problemi e prospettive. Siena: Protagon Editore Toscani. 
DONATI, L. (2004). "Il sacrificio umano",Thesaurus Cultus et Rituum Antiquorum, 1, 136-139. Los Ángeles, CA: Getty Publications.

GALLI, E.(1916). "Il sarcofago etrusco di Torre San Savero con quatro scene del ciclo trojano", Monumenti antichi, 5-118. Roma: Accademia dei Lincei

HARRISON, E. (1981). "Motifs of the city-siege on the shield of Athena Parthenos", American Journal of Archaeology, 85(3), 281-317. Boston, MA: Archaeological Institute of America.

HAYNES, S. (2000). Etruscan Civilization: A Cultural History. Los Angeles: The J. Paul Getty Museum.

HEURGON, J. (1961). La vie quotidienne chez les étrusques. Paris: Hachette.

MACINTOSH-TURFA, J. (1986). "International Contacts: Commerce, Trade, and Foreign Affairs". En: L. Bonfante (ed.), Etruscan Life and Afterlife. Warminster: Aris \& Phillips.

MAGGIANI, A. (1985). "Il sacrificio dei prigioneri troiani". En:Id. (ed.), Artigianato artistico: L'Etruria settentrionale interna in età ellenistica. Milan: Electa.

MARTELLI, M. (1975). "Un aspetto del commercio di manufatti artistici nel IV secolo a.C.: I sarcofagi in marmo", Prospettiva, 3, 9-17. Florencia: Centro Di.

MASSA-PAIRAULT, F.H. (1992). Iconologia e Politica nell'Italia Antica. Milan: Longanesi.

MINDER, E. (2008). "Una fonte etrusca per la storia romana: la Tomba François". En: La pittura etrusca: Atti del IV corso di perfezionamiento (anno 2005-2006). Orvieto: Quasar.

MUSTI, D. (2005). "Temi etici e politici nella decorazione pittorica della Tomba François". En: O. Paoletti (ed.), Dinamiche di sviluppo delle cittá nell'Etruria meridionale. Pisa - Roma: Instituti Editoriali e Poligrafici Internazionali.

POUZADOUX, C. (2013). Éloge d'un prince daunien: mythes et images en Italie méridionale au IVe siècle av. J.-C. Roma: École française de Rome.

PALLOTTINO, M. (1952). Etruscan Painting. Geneve : Skyra.

SCHMIDT, M. (1960). Der Dareios maler und sein Umkreis. Munster Westf. Munich: Aschendorff.

STEUERNAGEL, D. (1998). Menschenopfer und Mord am Altar. Griechische Mythen in etruskischen Gräbern (DAI Palilia 3). Wiesbden: Deutsches Archäologisches Institut.

TAPLIN, O. (2007). Pots and Plays: Interaction between Tragedy and Greek Vase-Painting of the Fourth Century. Los Angeles: The J. Paul Getty Museum. 
VAN DER MEER, L.B. (1985). "Thematische Symmetrie in der etruskischen Kunst", Bulletin antiekebeschaving: Annual Papers on Classical Archaeology, 60, 72-83. Leuven: Peeters Publishers.

-, (2004). Myths and More: On Etruscan Stone Sarcophagi (c. 350- c. 200 B.C.). Louvain: Dudley.

STEINGRÄBER, S. (1986). Etruscan Painting: Catalogue Raisoneé of Etruscan Wall Painting. D. Ridgway and F. Serra Ridgway (eds.). New York: Harcourt Brace Jovanovich. 